Instrumental Achievements

\title{
Crystal Structure of (Aqua)bis(dimethylglyoximato)((Z)-2- phenylethen-1-yl)cobalt(III)hydrate
}

\author{
Taro Yamada and Yuji OHASHI \\ Department of Chemistry, Tokyo Institute of Technology, O-okayama, Meguro, Tokyo 152, Japan
}

Many photoreactions of cobaloxime complexes in the solid or crystalline state have been found: e.g. photoracemization ${ }^{1}$ and photoisomerization. ${ }^{2}$ Since it is expected that the cobaloxime complex having an alkyl group with $\mathrm{C}-\mathrm{C}$ double bonds will show photoreactivity in the solid state, the alkenyl cobaloxime, ( $Z$ ) -2 phenylethen-1-yl)cabaloxime complex ${ }^{3}$, attracted our attention.

The title compound was prepared in a similar way to that reported previously. Single crystals suitable for $\mathrm{X}$-ray work were obtained from an aqueous methanol solution. The crystal is photostable to the irradiation of a Xe-lamp. The crystal data and the experimental details are listed in Table 1. The molecular and crystal structures are shown in Figs. 1 and 2, respectively. The atomic coordinates are listed in Table 2. The configuration of the alkenyl moiety is $Z$, which is consistent with the result from the ${ }^{1} \mathrm{H}$ NMR measurement. ${ }^{4}$ The molecule has an expanded alkenyl moiety; the bond angle $\mathrm{Col}-\mathrm{C} 9=\mathrm{C} 10, \mathrm{C} 9=\mathrm{C} 10-\mathrm{C} 11$ and $\mathrm{O} 5-\mathrm{Co} 1-\mathrm{C} 9$ are

Table 1 Crystal and experimental data

\begin{tabular}{ll}
\hline Formula & $\mathrm{C}_{16} \mathrm{H}_{25} \mathrm{O}_{6} \mathrm{~N}_{4} \mathrm{Co} \cdot \mathrm{H}_{2} \mathrm{O}$ \\
$M_{\mathrm{r}}=428.33$ & triclinic \\
Crystal system & $P 1$ \\
Space group & $\alpha=94.95(4)$ \\
$a=10.405(5) \AA$ & $\beta=102.08(4)^{\circ}$ \\
$b=13.032(5) \AA$ & $\gamma=104.07(3)^{\circ}$ \\
$c=7.507(4) \AA$ & $Z=2$ \\
$V=955.3(7) \AA^{3}$ & \\
$D_{\mathrm{x}}=1.489 \mathrm{Mg} \mathrm{m}^{-3}$ & \\
$\lambda=0.71073 \AA\left(\mathrm{MoK}_{\alpha}\right)$ & \\
$T=296 \mathrm{~K}$ & Rigaku AFC-5 \\
Diffractometer & $0.62 \times 0.30 \times 0.12 \mathrm{~mm}$ \\
Crystal size & red \\
Crystal color & plate \\
Crystal description & \\
$\omega / 2 \theta$ scans & 4390 independent reflections \\
$\theta_{\max }=27.52^{\circ}$ & 3295 observed reflections $P 2 \sigma(I)]$ \\
250 parameters & \\
$R(F>4 \sigma(F))=0.048$ & \\
$w R\left(F^{2}\right)=0.119$ & \\
Structure determination & SHELXS-86 \\
Refinement & SHELXL-937 \\
\hline
\end{tabular}

$135.6(2)^{\circ}, 133.1(3)^{\circ}$ and $176.2(1)^{\circ}$, respectively. The cobaloxime plane is distorted like a propeller because of the close contact with the alkenyl group; the torsion angles between two dimethylglyoxime moieties O1$\mathrm{N} 1 \cdots \mathrm{N} 4-\mathrm{O} 4$ and $\mathrm{O} 2-\mathrm{N} 2 \cdots \mathrm{N} 3-\mathrm{O} 3$ are $5.4(2)^{\circ}$ and

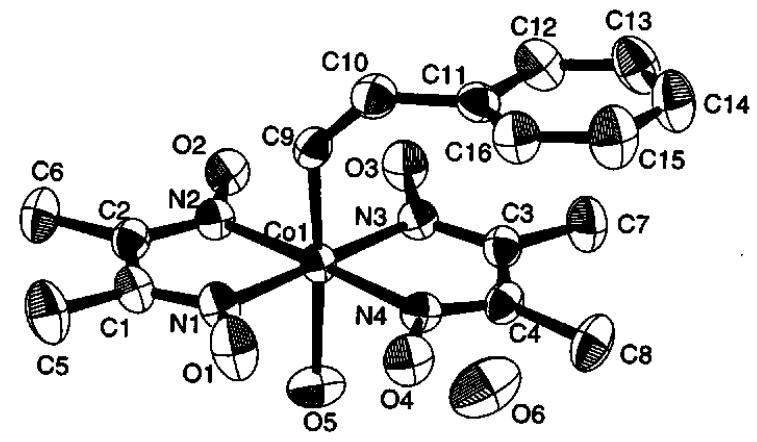

Fig. 1 ORTEP ${ }^{8}$ drawing with the numbering of the atoms. Thermal ellipsoids scaled to enclose $50 \%$ probability.

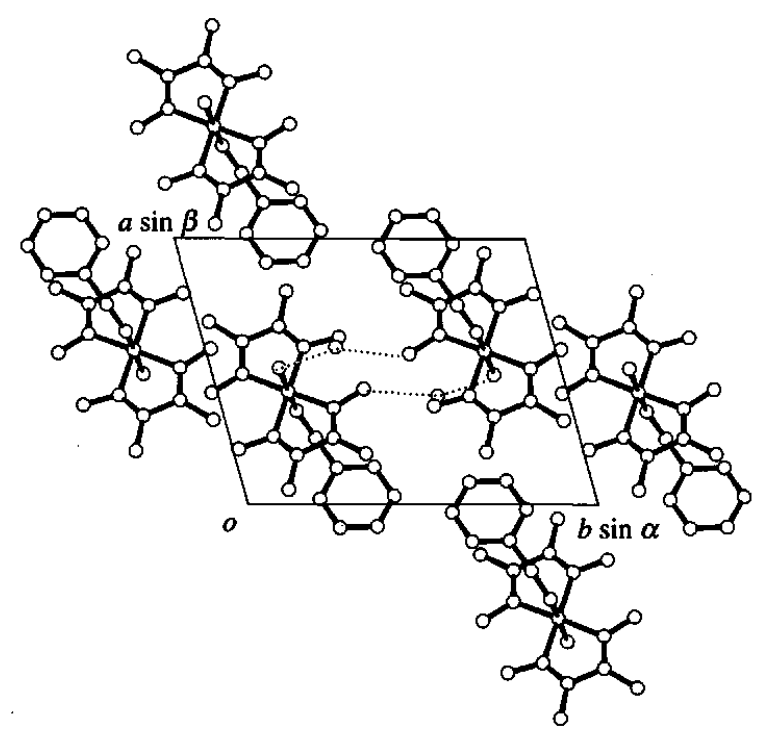

Fig. 2 Crystal structure viewed along the $c$ axis. Intermolecular hydrogen bonds are indicated by dotted lines. 
Table 2 Fractional atomic coordinates and equivalent isotropic displacement parameters $\left(\AA^{2}\right)$ for non-hydrogen atoms

\begin{tabular}{lrrrr}
\hline Atom & \multicolumn{1}{c}{$\boldsymbol{x}$} & \multicolumn{1}{c}{$\boldsymbol{y}$} & $\boldsymbol{z}$ & \multicolumn{1}{c}{$U_{\text {eq }}$} \\
\hline $\mathrm{Co}(1)$ & $0.4230(1)$ & $0.2036(1)$ & $0.1563(1)$ & 0.027 \\
$\mathrm{O}(1)$ & $0.6286(3)$ & $0.3910(2)$ & $0.3513(4)$ & 0.056 \\
$\mathrm{O}(2)$ & $0.4176(2)$ & $-0.0157(2)$ & $0.1742(3)$ & 0.037 \\
$\mathrm{O}(3)$ & $0.2070(2)$ & $0.0175(2)$ & $-0.0175(3)$ & 0.043 \\
$0(4)$ & $0.4337(2)$ & $0.4209(2)$ & $0.1279(3)$ & 0.046 \\
$0(5)$ & $0.5120(3)$ & $0.1959(2)$ & $-0.0633(3)$ & 0.048 \\
$\mathrm{O}(6)$ & $0.4090(4)$ & $0.6266(2)$ & $0.2242(4)$ & 0.078 \\
$\mathrm{~N}(1)$ & $0.5916(2)$ & $0.2825(2)$ & $0.3123(4)$ & 0.037 \\
$\mathrm{~N}(2)$ & $0.4894(2)$ & $0.0866(2)$ & $0.2329(3)$ & 0.031 \\
$\mathrm{~N}(3)$ & $0.2542(2)$ & $0.1259(2)$ & $0.0022(3)$ & 0.031 \\
$\mathrm{~N}(4)$ & $0.3612(2)$ & $0.3191(2)$ & $0.0707(3)$ & 0.032 \\
$\mathrm{C}(1)$ & $0.6689(3)$ & $0.2287(3)$ & $0.3933(4)$ & 0.038 \\
$\mathrm{C}(2)$ & $0.6108(3)$ & $0.1119(2)$ & $0.3429(4)$ & 0.034 \\
$\mathrm{C}(6)$ & $0.6845(4)$ & $0.0328(3)$ & $0.4132(5)$ & 0.048 \\
$\mathrm{C}(5)$ & $0.8015(4)$ & $0.2777(3)$ & $0.5308(6)$ & 0.058 \\
$\mathrm{C}(7)$ & $0.0544(3)$ & $0.1275(3)$ & $-0.2353(5)$ & 0.051 \\
$\mathrm{C}(3)$ & $0.1844(3)$ & $0.1788(2)$ & $-0.0975(4)$ & 0.034 \\
$\mathrm{C}(4)$ & $0.2487(3)$ & $0.2950(2)$ & $-0.0566(4)$ & 0.034 \\
$\mathrm{C}(8)$ & $0.1900(4)$ & $0.3767(3)$ & $-0.1474(5)$ & 0.052 \\
$\mathrm{C}(9)$ & $0.3511(3)$ & $0.2115(2)$ & $0.3732(4)$ & 0.034 \\
$\mathrm{C}(10)$ & $0.2489(3)$ & $0.2445(3)$ & $0.4176(4)$ & 0.042 \\
$\mathrm{C}(11)$ & $0.1361(3)$ & $0.2819(3)$ & $0.3101(4)$ & 0.036 \\
$\mathrm{C}(12)$ & $0.0186(3)$ & $0.2092(3)$ & $0.2019(5)$ & 0.046 \\
$\mathrm{C}(13)$ & $-0.0895(4)$ & $0.2436(3)$ & $0.1109(6)$ & 0.054 \\
$\mathrm{C}(14)$ & $-0.0840(4)$ & $0.3508(3)$ & $0.1273(6)$ & 0.058 \\
$\mathrm{C}(15)$ & $0.0307(4)$ & $0.4238(3)$ & $0.2361(6)$ & 0.059 \\
$\mathrm{C}(16)$ & $0.1398(4)$ & $0.3895(3)$ & $0.3270(5)$ & 0.046 \\
\hline & & & \\
\hline
\end{tabular}

$U_{\mathrm{eq}}=(1 / 3) \Sigma_{i} \Sigma_{j} U_{i j} a_{i}^{*} a_{j}^{*}\left(a_{i} \cdot a_{j}\right)$.

$4.2(2)^{\circ}$, respectively. The phenyl group is almost parallel to the cobaloxime plane and nearly perpendicular to the alkenyl plane; the torsion angle $\mathrm{C} 9=\mathrm{C} 10$ C11-C12 is $80.9(5)^{\circ}$, showing that the conjugation is interrupted between the phenyl and the vinyl group. The geometry of the alkenyl group is almost the same as that of [1-chloro-2,2-bis( $p$-chlorophenyl)vinyl]bis(dimethylglyoximato)pyridine cobalt(III) reported previouslys, in which one of the $p$-chlorophenyl groups was imposed to be cis to the cobaloxime plane.

Figure 2 shows the crystal structure. The phenyl group is parallel to the cobaloxime plane of the adjacent molecules. The solvent water molecule 06 is hydrogenbonded to the cobaloxime plane $\mathrm{O} 4$ and the axial water ligand $05 ; 06 \cdots 04$, and $06[1-x, 1-y,-z] \cdots 05$ are 2.80 , and $2.73 \AA$ respectively. These hydrogen bonds make a dimer around the inversion center $(0.5,0.5,0)$.

The author (T. Y.) would like to gratefully acknowledge the JSPS Research Fellowships for Young Scientists.

\section{References}

1. Y. Ohgo and Y. Ohashi, Bull. Chem. Soc. Jpn., 69, 2425 (1996).

2. H. Amano and Y. Ohashi, Bull. Chem. Soc. Jpn., 69, 3107 (1996).

3. G. N. Schrauzer and R. J. Windgassen, J. Am. Chem. Soc., 89, 1999 (1967).

4. D. Dodd and M. D. Johnson, J. Organomet. Chem., 52, 1 (1973).

5. D. A. Stotter, G. M. Sheldrick and R. Taylor, J. Chem. Soc., Dalton Trans., 1975, 2124.

6. G. M. Sheldrick, Acta Crystallogr., A46, 467 (1990).

7. G. M. Sheldrick, SHELXL-93. Program for Crystal Structure Determination. Univ. of Göttingen, Germany (1993).

8. C. K. Johnson, ORTEPII. Report ORNL-5138. Oak Ridge National Laboratory, Tennessee, USA (1976).

(Received March 13, 1997) (Accepted April 28, 1997) 